\title{
Robust ANFIS Vector Control of Induction Motor Drive for High-Performance Speed Control Supplied by a Photovoltaic Generator
}

\author{
CHIHEB BEN REGAYA, FETHI FARHANI, HICHEM HAMDI \\ ABDERRAHMEN ZAAFOURI, ABDELKADER CHAARI
}

ISSAT KAIROUAN - Institut Supérieur des Sciences Appliquées et de Technologie de KairouanIndustrial Systems Engineering and Renewable Energies ResearchLaboratory, Higher National Engineering School of Tunis (ENSIT)1008 Tunis, TUNISIA

\begin{abstract}
This paper presents the vector control of Induction Motor (IM) supplied by a photovoltaic generator which is controlled by an adaptive Proportional-Integral (PI) speed controller. The proposed solution is used to overcome the induction motor rotor resistance variation problem, which can affect negatively the performance of the speed control. To overcome the rotor resistance variation, an adaptive Proportional-Integral controller is developed with gains adaptation based on Adaptive Neuro-Fuzzy Inference System (ANFIS) in order to guarantee a high performances of electric drive systems against the parametric variations. The proposed control algorithm is tested by Matlab-Simulink. Analysis of the obtained results shows the characteristic robustness to disturbances of the load torque and to rotor resistance variation compared to the classical PI control and Model Reference AdaptiveSystem(MRAS)rotorresistanceobservers.
\end{abstract}

Key-Words: Induction motor, Adaptive control, Adaptive Neuro-Fuzzy Inference System, PI gains adaptation, Vectorcontrol,Photovoltaicsystems,MPPT.

Received: January 16, 2020. Revised: August 1, 2020. Accepted: August 17, 2020. Published: September 9, 2020.

\section{Introduction}

Renewable energies, such as, such as solar energy, wind energy, biomass energy, and hydro power come from the sun, wind, biomass, water and heat. Today, solar energy is considered one of the most reliable sources of energy available on a daily basis, respectful of nature and free. The exploitation of this renewable energy to produce electricity is carried out using a photovoltaic system [1]. The remotely isolated rural areas pose problems to rural energy management and development of renewable energy sources. The PhotoVoltaic panel (PV) is non-linear system, which its optimum operating point ("Maximum Power Point (MPP)") depends on the irradiation, the temperature and the load variations. The extraction of the maximum power from a $\mathbf{P V}$ is ensured by the Maximum Power Point Tracking (MPPT) algorithm. Among the most used MPPT algorithms we can cite: the traditional perturbation and observation method $(\mathrm{P} \& \mathrm{O})$ and the incremental conductance method (I.C) ([2],[3]).

Recent reports on the consumption of electrical energy, show that $40 \%$ of that produced in the world is consumed by electric motors, of which $90 \%$ are induction motors ([4],[5],[6]). Indeed, about $70 \%$ of industrial control systems use induction motors, due to their robustness, low cost and easy maintenance ([7],[8],[9],[11]). However, these advantages are accompanied by a great complexity related to the nonlinearity of induction motor model, or to the measurable quantities number limitation [10]. Therefore, several researches have been devoted to improving their performances despite their control complexities depending on the desired performance. The first control applications of induction motors were limited only to steady state. These applications were based on the scalar control, also known by $(V / f)^{1}$ control, which is characterized by its simplicity and low cost of implantation. Nevertheless, the scalar control cannot guarantee a high performance due to the existence of an intrinsic coupling between torque and flux.

In recently years, the technological advances in power electronics fields and signal processing make possible

\footnotetext{
${ }^{1}$ The principle of the scalar control is to maintain a constant ratio between the voltage $(V)$ and the frequency $(f)$, and the torque control is done by the action on the slip angular frequency.
} 
the design of a complex real time implementation control algorithms. The first control techniques that have been developed to overcome the drawbacks of the scalar control are: the Field Oriented Control (FOC) and the Direct Torque Control (DTC) ([12],[13]). In the literature, there are many field oriented control strategies that differ essentially in the choice of the $(d-q)$ axes orientation. The most common is the Rotor Field Oriented Control (RFOC) ([14],[15]). The RFO control techniques differ mainly in the method of determining the Park angle, which represents the field oriented phase in the reference related to the stator. In the case where the flux amplitude and the Park angle are determined from the voltages measurement, currents and electrical rotor frequency, this control method is called Direct Rotor Field Oriented Control (DRFOC) [16]. On the other hand, in the case of the Indirect Rotor Field Oriented Control (IRFOC), the stator currents and the rotor speed are the only ones that must be measured to determine the Park angle ([17],[18]). The IRFOC is the most used in the industry over the past decades, because of its simple implementation and does not require a flux sensor as in DRFO control. The performance of the IRFO control strategy depend heavily on the knowledge of the real motor parameters, particularly with respect to the rotor resistance variation, which is considered as the most critical changing parameter ([9],[10],[19],[20]). To solve the problem of parametric variations, many research have been developed based on the adaptive control in order to improve the robustness of the control scheme. Among them, the adaptive control of IM based on sliding mode observer [21] which shows that the main drawback of this solution is the appearance of the chattering phenomenon. The Model Reference Adaptive Systems (MRAS) observer, is another solution presented in literature to overcome the rotor resistance variation, but in ([22],[23]), the authors show that this method doesn't guarantee a high performance of speed control. The works presented by ([10],[19],[24],[25]), which concerns the luenberger and the backstepping observers, show that the use of this type of adoptive control induction motor can lead to the instability problems especially at low speed, if the estimation error of the rotor resistance is greater than its nominal value by $10 \%$.

The main purpose of this paper is to design an adaptive control scheme for induction motor that allow high performance using the Adaptive Neuro-Fuzzy Inference System. The idea is to design an adaptive PI speed controller which can ensure a good tracking of the reference speed even in the presence of rotor resistance variation. The adaptive mechanism of the PI gains is ensured using an adaptive neuro-fuzzy controller for each gain $\left(k_{p}\right.$ and $\left.k_{i}\right)$. The control law de- veloped in this paper does not propose the use of any observer mentioned above so as not increase the complexity of the control scheme, and guarantee a good rotor flux orientation even in the case of rotor resistance variation.

This paper is organized as follows: in Section 2, the mathematical model of the induction motor, vector control, PV panel and DC-DC boost converter are presented. In Section 3, the adaptive neuro-fuzzy controller (ANFIS) for the PI controller gains adaptation is presented. Simulation results are presented in Section 4, and compared with classical PI control and other adaptive control. Finally, in Section 5 some comments and conclusion are given.

\section{System descriptions}

The block diagram of the robust ANFIS vector control is shown in Figure 1, which contain a PV array, a boost converter working as a maximum power point tracker (MPPT), an inverter and a motor motor controlled by the proposed control algorithm.

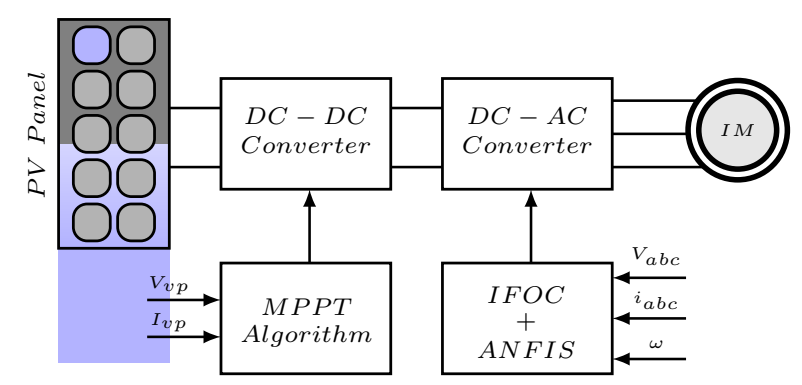

Figure 1: Synoptic diagram of the photovoltaic system and induction motor.

\subsection{Dynamic model of IM and problem for- mulation}

The IM dynamic mathematical model can be expressed in the $(d-q)$ rotaionnal reference frame as follows:

$$
\begin{gathered}
\frac{d}{d t} i_{s d}=-\lambda i_{s d}+\omega_{s} i_{s q}+\frac{R_{r} M}{\sigma L_{r}^{2} L_{s}} \phi_{r d}+\frac{M}{\sigma L_{r} L_{s}} \omega_{r} \phi_{r q}+\frac{1}{\sigma L_{s}} v_{s d} \\
\frac{d}{d t} i_{s q}=-\lambda i_{s q}-\omega_{s} i_{s d}-\frac{M}{\sigma L_{r} L_{s}} \omega_{r} \phi_{r d}+\frac{R_{r} M}{\sigma L_{r}^{2} L_{s}} \phi_{r q}+\frac{1}{\sigma L_{s}} v_{s q} \\
\frac{d}{d t} \phi_{r d}=\frac{M R_{r}}{L_{r}} i_{s d}-\frac{R_{r}}{L_{r}} \phi_{r d}+\omega_{s l} \phi_{r q} \\
\frac{d}{d t} \phi_{r q}=\frac{M R_{r}}{L_{r}} i_{s q}-\omega_{s l} \phi_{r d}-\frac{R_{r}}{L_{r}} \phi_{r q}
\end{gathered}
$$


where

$$
\begin{array}{cl}
v_{s d}, v_{s q} & : d \text { and } q \text { components of stator voltages; } \\
i_{s d}, i_{s q} & : d \text { and } q \text { components of stator currents; } \\
\phi_{r d}, \phi_{r q} & : d \text { and } q \text { rotor flux components; } \\
L_{s}, L_{r} & : \text { Stator and rotor inductances; } \\
R_{s}, R_{r} & : \text { Stator and rotor resistances; } \\
M, \sigma & : \text { Mutual inductance and total linkage coefficient; } \\
\omega_{r}, \omega_{s} & : \text { Rotor and rotating frame angular velocity; } \\
\omega_{s l}=\omega_{s}-\omega_{r} & : \text { Slip angular frequency. }
\end{array}
$$

One of the most technical used to control the induction motor is called Field Oriented Control FOC, which allow the conversion of the three-phase stator currents of an $\mathrm{AC}$ electric motor into two orthogonal components that can be considered as vectors. The first one allows adjustment of the magnetic flux of the motor, while the second control the torque. In this case, the control of AC motor becomes like that of a DC motor, and allows to write:

$$
\begin{array}{ll}
\phi_{r d} & =\phi_{r} \\
\phi_{r q} & =0
\end{array}
$$

Based on what is mentioned above, the mathematical dynamic model of IM (1) is transformed to a linear model and is described by the following equations:

$$
\begin{gathered}
\frac{d}{d t} i_{s d}=f_{1}+\mu v_{s d} \\
\frac{d}{d t} i_{s q}=f_{2}+\mu v_{s q} \\
\frac{d}{d t} \phi_{r d}=\frac{M}{\tau_{r}} i_{s d}-\frac{R_{r}}{L_{r}} \phi_{r d} \\
\frac{d}{d t} \phi_{r q}=0=\frac{M}{\tau_{r}} i_{s q}-\omega_{s l} \phi_{r d}
\end{gathered}
$$

where

$f_{1}=-\lambda i_{s d}+\omega_{s} i_{s q}+\frac{R_{r} M}{\sigma L_{r}^{2} L_{s}} \phi_{r d}+\frac{M}{\sigma L_{r} L_{s}} \omega_{r} \phi_{r q} ;$

$f_{2}=-\lambda i_{s q}-\omega_{s} i_{s d}-\frac{M}{\sigma L_{r} L_{s}} \omega_{r} \phi_{r d}+\frac{R_{r} M}{\sigma L_{r}^{2} L_{s}} \phi_{r q} ;$

$\tau_{r}=\frac{L_{r}}{R_{r}}$ and $\mu=\frac{1}{\sigma L_{s}}$.

The mechanical equation, the electromagnetic torque and the slip frequency are is given by the following equations:

$$
\begin{gathered}
\frac{d}{d t} \Omega_{r}=-\frac{f}{J} \Omega_{r}+\frac{1}{J}\left(\Gamma_{e}-\Gamma_{l}\right) \\
\Gamma_{e}=\frac{3}{2} \frac{n_{p} M}{L_{r}}\left(\phi_{r d} . i_{s q}\right) \\
\omega_{s l}=\frac{M}{\tau_{r} \phi_{r}} i_{s q}
\end{gathered}
$$

where

$\Gamma_{e}, \Gamma_{l} \quad$ : Electromagnetic and load torques;

$J, f \quad$ : The inertia of motor and friction coefficient;

$n_{p} \quad$ : Number of pole pairs.
Equations (3) and (4) show the non-linearity of the induction motor which can be solved by adding the compensations terms as illustrated in Figure 2. Also, we can note that the slip angular frequency $\omega_{s l}$ depends on rotor resistance, and a mismatch of the latter doesnt guarantee a high-performance speed control.

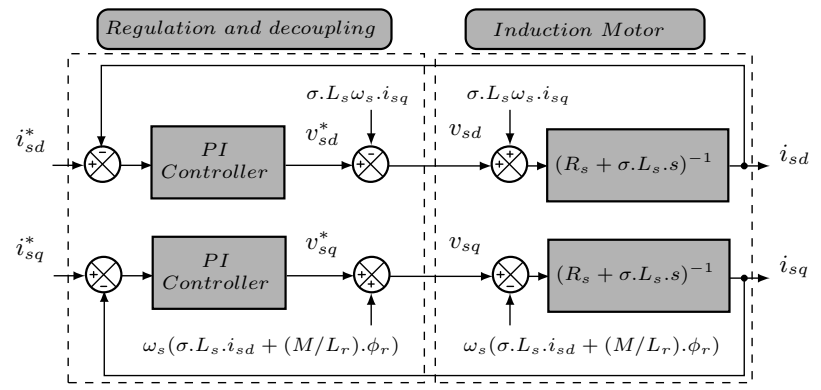

Figure 2: Structure of the compensation coupling terms.

The PI speed controller determines the reference torque to maintain the same speed. So, to calculate the parameters of the controller, it must be assumed that the dynamics of the stator currents is not involved in the dynamics of the speed control loop because the mechanical constant time is considerably greater than the electric constant time. The correction gains of the PI controller are determining using pole placement method to fix the closed-loop system dynamics, which are presented in [26] by the following equations:

$$
\begin{gathered}
k_{p}=\frac{2 \xi k_{i}}{\omega_{n}}-\frac{f}{K_{\Gamma_{e}}} \\
k_{i}=\frac{J \omega_{n}^{2}}{K_{\Gamma_{e}}}
\end{gathered}
$$

where $\xi$ is the damping ratio, $\omega_{n}$ the natural frequency and $K_{\Gamma_{e}}=\frac{3}{2} \frac{n_{p} M}{L_{r}} \phi_{r}$ the electromagnetic torque constant.

\subsection{Photovoltaic array model}

The operation of a photovoltaic cell is often described by the single diode model, this model is generalized to a photovoltaic module by considering it as a set of identical cells connected in series and/or in parallel. The modeling of the elementary cell is based on an equivalent electrical circuit [27]. In this study we use a single diode model shown in Figure 3.

The PV panel is composed of $N_{P}$ parallel modules. Each one including $N_{S}$ serial connected photovoltaic cell serial. The fundamental equation for PV model is given by [2]:

$$
I_{p v}=N_{p} I_{p h}-N_{p} I_{0}\left[\exp \left(\frac{q\left(V_{p v}+I_{p v} R_{s}\right)}{a k T N_{s}}\right)-1\right]-\frac{V_{p v}+I_{p v} R_{s}}{R_{s h}}
$$




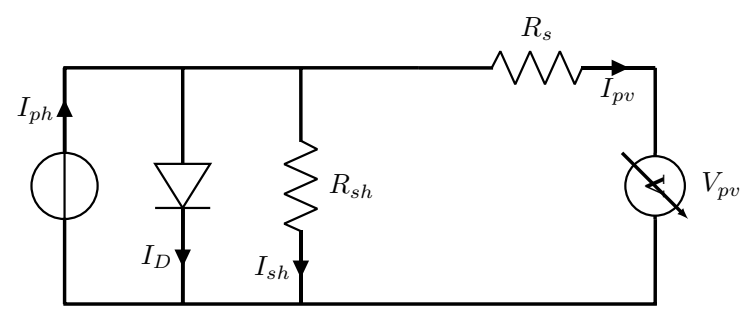

Figure 3: General PV Cell Model.

$$
\begin{gathered}
I_{0}=I_{0 r}\left(\frac{T}{T_{r e f}}\right)^{3} \cdot \exp \left[\frac{q E_{G}}{k \cdot a}\left(\frac{1}{T_{r e f}}-\frac{1}{T}\right)\right] \\
I_{p h}=\left[I_{s c}+k_{T}\left(T-T_{r e f}\right)\right] \frac{G}{G_{r e f}}
\end{gathered}
$$

where:

$I_{p v}$ :Output current of solar cells (Ampere);

$I_{p h}:$ Photocurrent (Ampere);

$V_{p v}$ :Output voltage of solar cells (Volt);

$R_{s h}, R_{s}$ :Parallel and series resistance, respectively;

$q$ :Electron charge $\left(1.60222 \times 10^{-19} C\right)$;

$k$ :Boltzmanns constant $\left(1.381 \times 10^{-23} \mathrm{~J} / \mathrm{K}\right)$;

$a: P-N$ junction ideality factor;

$I_{0}, I_{0 r}$ :Real and reference cell reverse saturation current, respectively;

$K_{T}$ :Temperature coefficient of the short circuit current;

$T, T_{\text {ref }}:$ Reference temperature of Solar Cells (Kelvin);

$G, G_{r e f}:$ Irradiance and reference irradiance;

$E_{G}:$ Silicon bandgap energy $\left(E_{g}=1.12 \mathrm{eV}\right)$;

$I_{s c}$ :Short-circuit current.

\subsection{Boost converter model}

The power generated by the photovoltaic panel is fed to a boost converter, which is controlled using an MPPT controller based on Perturb and Observe technique $(\mathbf{P} \& \mathbf{O})$. The boost converter is used to amplify the generated DC voltage of the panel. The Duty (D) cycle for switching is determined by the Maximum Power Point Tracking (MPPT) controller, which determines the present climatic condition and produces an optimum value of duty cycle, as shown in Figure 4.

In steady state, the output voltage of the boost converter can be expressed by the following equation:

$$
U_{R}=\frac{1}{1-D} V_{p v}
$$

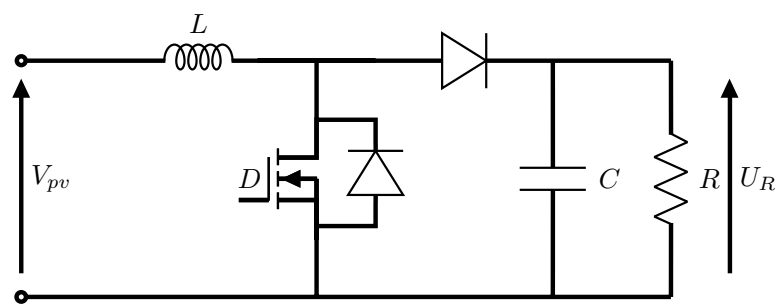

Figure 4: Boost converter.

\section{ANFIS Control Based on PI Gains Adaptation}

The adaptive neuro-fuzzy inference is designed based on a combination of Artificial Neural Network (ANN) and Fuzzy Logic Controller (FLC). The ANN is used to identify the patterns and conforms to them to deal with altering environments, and the Fuzzy Inference Systems (FIS) combine the human knowledge to control the system ([2],[28]).

Two common fuzzy models, the Mamdani and Takagi-Sugeno-Kang (TSK), are defined for FIS. The ANFIS can only use the TSK fuzzy model due to its high calculative efficiency. The controller provides smooth less in convergence because of the fuzzy TSK inference and adaptability as a result of ANN backpropagation algorithms. The general structure of a five-layer ANFIS system is shown in Figure 5. For the first layer, MFs will be defined for each of inputs.In the second layer, each node via multiplication calculates the firing strength of a rule which is normalized in layer 3. Two common rules in TSK fuzzy model are defined as:

Rule 1 : if $x$ is $A_{1}$ and $y$ is $B_{1}$, then $f_{1}=a_{1} x+b_{1} y+$ $c_{1}$;

Rule 2 : if $x$ is $A_{2}$ and $y$ is $B_{2}$, then $f_{2}=a_{2} x+b_{2} y+$ $c_{2}$.

Where $a_{i}, b_{i}$ and $c_{i}$ are the design parameters defined in the training plant. Also, $A_{i}$ and $B_{i}$ are the fuzzy sets input.

The model structure is determined using the inputs, output, MFs, and the relationship among them in Matlab environment. After that, the inputs and output training data set should be collected to train the ANFIS which can estimate the MFs parameters by either back propagation algorithms alone or the so-called hybrid mode which is a combination of Least Squares Estimation (LSE) and back propagation.

The adaptive PI controller structure whose parameters are adjusted by an adaptive neuro-fuzzy inference system. The ANFIS generates the parameters of the PI controller $k_{p}$ and $k_{i}$ depending on the error between the reference and the system response as shown in 


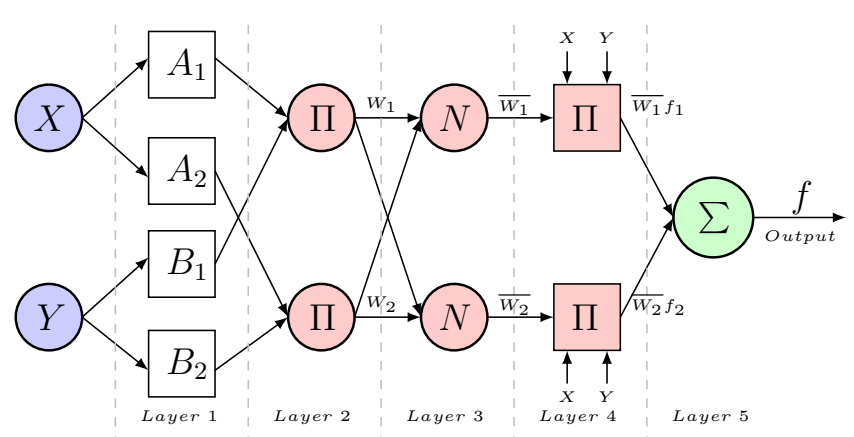

Figure 5: Five-layer ANFIS system.

Figure 6 to ensure high performance of the developed control law with compensation of the rotor resistance variation effect. The proposed controller uses two ANFIS: the first generates the $k_{p}$ gain and the second generates $k_{i}$ via another auxiliary parameter $\beta$. The adaptive neuro-fuzzy inference system of the PI controller is shown in Figure 7.

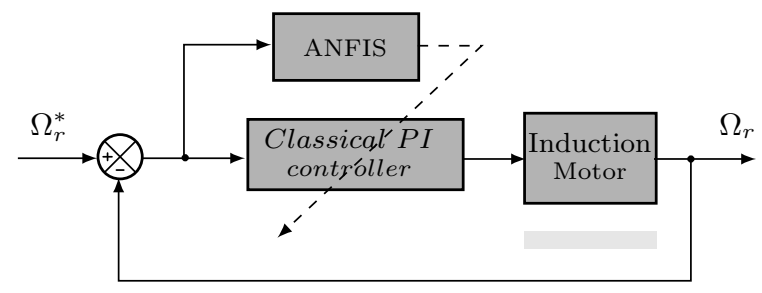

Figure 6: Block diagram of the ANFIS gains adaptation of the PI controller.

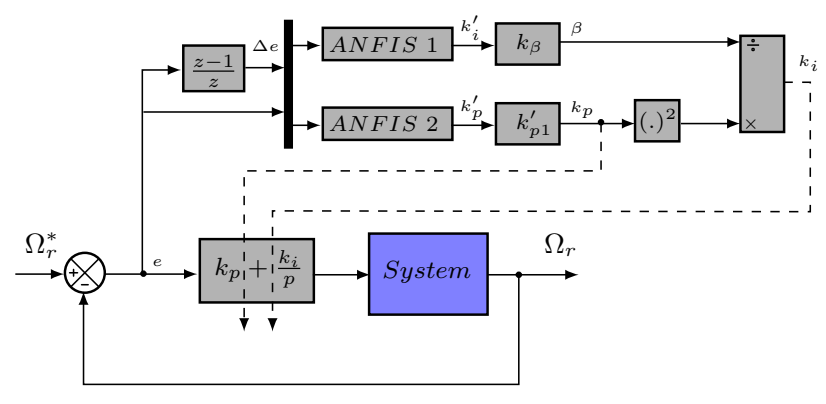

Figure 7: Block scheme of the proposed speed control loop using ANFIS.

As indicated in Figure 4, the PI parameters are determined from two adaptive neuro-fuzzy inference systems whose outputs are auxiliary parameters $k_{p_{1}}^{\prime}, k_{\beta}$ and inputs are the error between the real and reference speed $\left(e_{\Omega_{r}}\right)$, and its derivative $\left(\Delta e_{\Omega_{r}}\right)$.

The output of the two fuzzy controllers are standardized in intervals between zero and 1. The parameters $k_{p}$ and $k_{i}$ are determined using the following equations:

$$
\begin{gathered}
k_{p}=k_{p_{1}}^{\prime} k_{p}^{\prime} \\
k_{i}=\frac{k_{p}^{2}}{\beta}
\end{gathered}
$$

The Neural Network Controller (NNC) is used to estimate the PI controller gains. The network is trained for 1000 epochs and the target error is set to $2.4 \%$. The training error waveform is shown in Figure 8, and the structure of ANFIS for this controller is presented in Figure 9. The advantages of the method are its rapid tracking speed and high tracking accuracy.

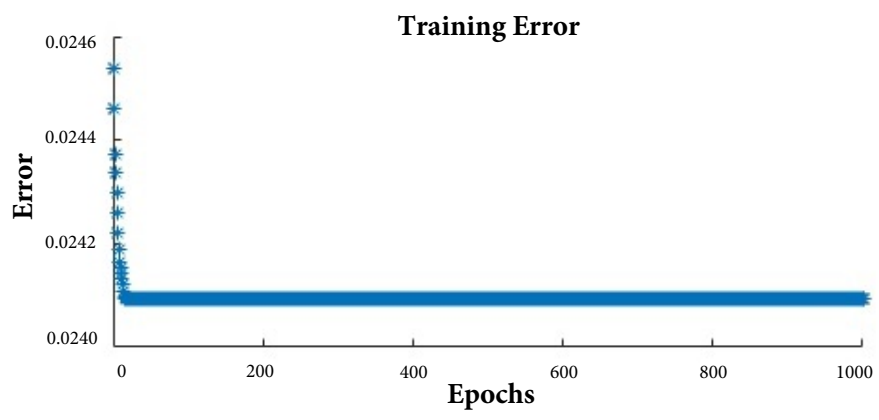

Figure 8: Training error.

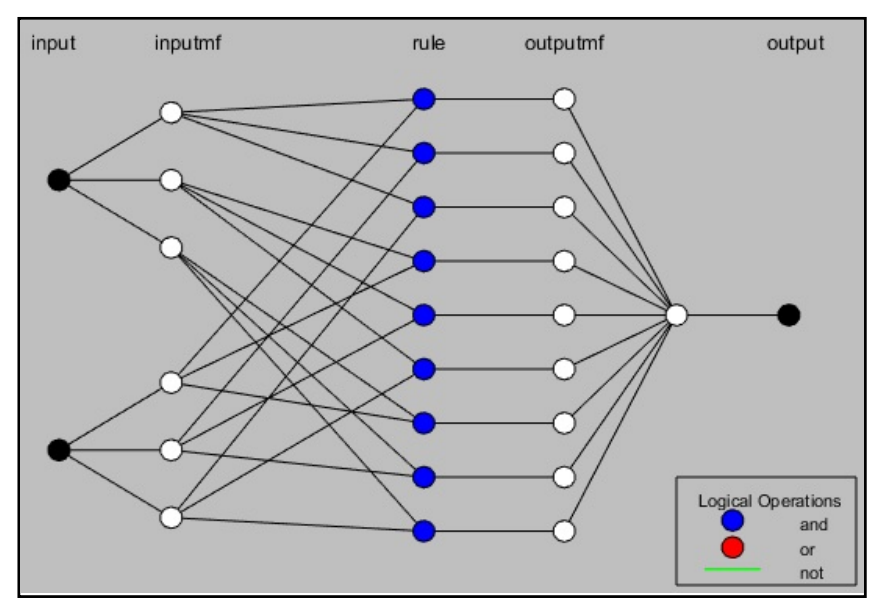

Figure 9: ANFIS model structure.

Figures 10 and 11 represent membership functions for the two inputs, namely, solar irradiance and PV cell temperature. Figure 12 shows a fuzzy rule for the ANFIS inputs and output are applied after training. 


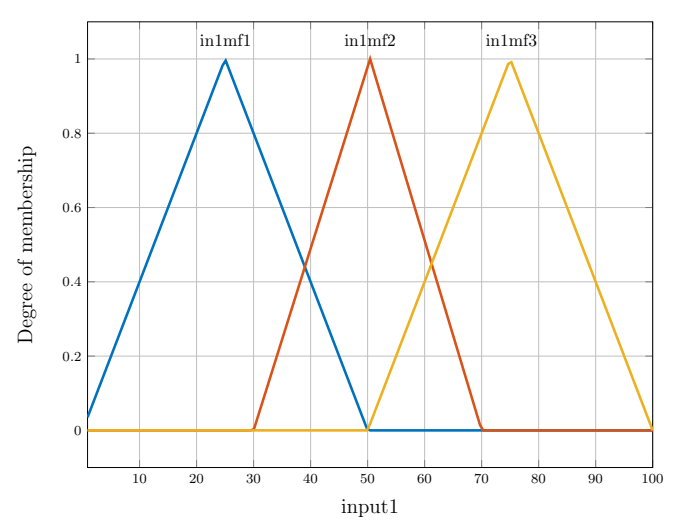

Figure 10: Membership functions for $e_{\Omega_{r}}$.

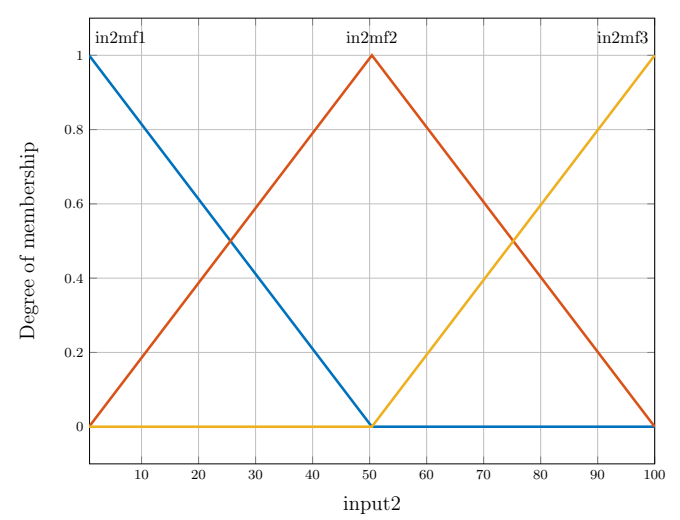

Figure 11: Membership functions for $\Delta e_{\Omega_{r}}$.

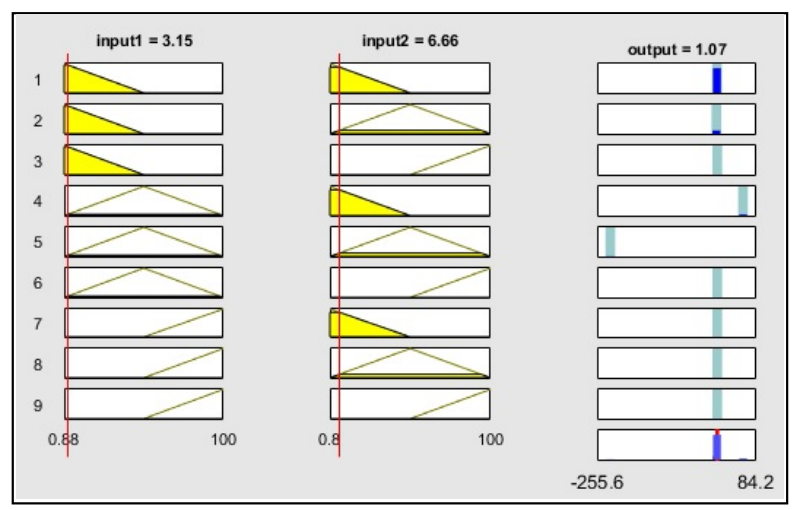

Figure 12: Inputs and Output of ANFIS after Training.
In order to verify the closed-loop stability of the proposed controller, the linear time-invariant transfer matrix of the closed loop transfer function ANFIS tuned PI speed controller expressed by equation 12 must be strictly positive real (i.e. All poles of $H(s)$ have negative real parts) for $\Gamma_{l}=0$.

$$
H(s)=(s I-A)^{-1}
$$

where, A the state space matrix of the closed-loop system of the ANFIS tuned PI speed controlled induction motor. The condition of stability is validated by the root locus study of $H(s)$ using the 'rlocus' command of Matlab. Figures 13 shows clearly that the poles and zeros of the transfer function $H(s)$ have negative real parts for a speed range between $-157 \mathrm{rad} / \mathrm{s}$ and $157 \mathrm{rad} / \mathrm{s}$ which indicates that the ANFIS tuned PI speed controlled induction motor under consideration is stable.

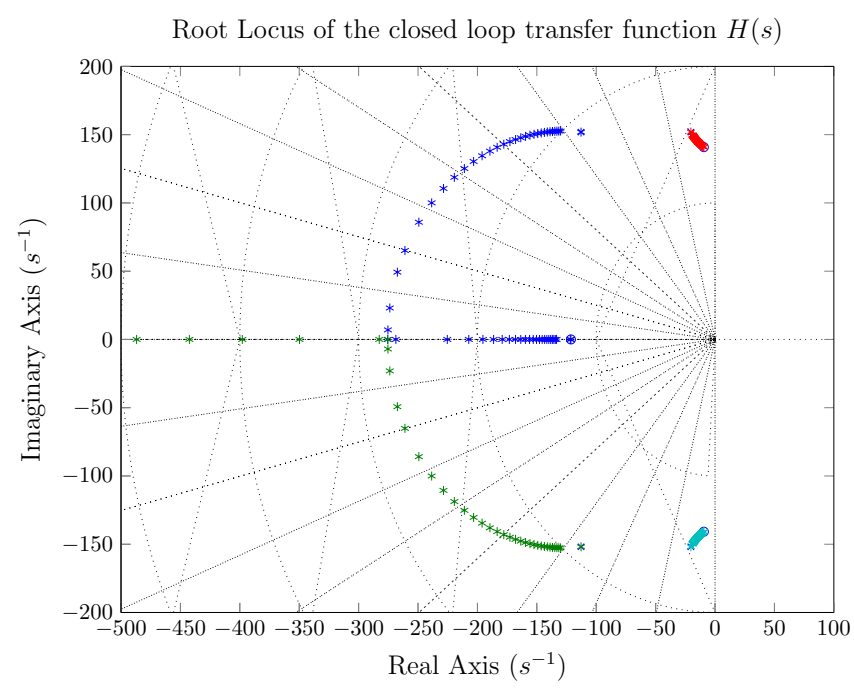

Figure 13: Poles localization for the transfer matrix $H(s)$ for $\Omega_{r}=0 \leftrightarrow \pm 157 \mathrm{rad} / \mathrm{s}$.

\section{Simulation Results and Discussion}

The proposed PI field oriented control of induction motor with gains adaptation based on ANFIS has been verified by simulations. The rotor field oriented control scheme is illustrated in Figure 14. The simulation results have been obtained by implementing the control scheme under the Matlab- Simulink environment with $50 \mu$ s sampling period. The motor parameters values of the set-up and the PV panel are given in Tables 1 and 2. The reference value of the rotor flux along the $\mathrm{d}$-axis has been fixed to $1 \mathrm{~Wb}$. 
Table 1: Motor parameters values.

\begin{tabular}{cccc}
\hline Symbol & & Quantity & UM \\
\hline \hline$R_{s}$ & Stator resistance & 2.3 & {$[\Omega]$} \\
$R_{r}$ & Rotor resistance & 1.83 & {$[\Omega]$} \\
$L_{s}$ & Stator inductance & 261 & {$[\mathrm{mH}]$} \\
$L_{r}$ & Rotor inductance & 261 & {$[\mathrm{mH}]$} \\
$M$ & Mutual inductance & 245 & {$[\mathrm{mH}]$} \\
$\sigma$ & Leakage factor & 0.134 & - \\
$J$ & Moment of inertia & 0.22 & {$\left[\mathrm{Kgm}^{2}\right]$} \\
$f$ & Friction coefficient & 0.001 & - \\
$V_{n}$ & Rated voltage & 380 & {$[\mathrm{~V}]$} \\
$I_{n}$ & Rated current & 10.4 & {$[\mathrm{~A}]$} \\
$P_{n}$ & Rated power & 3 & {$[\mathrm{~kW}]$} \\
$n_{p}$ & Number of pole pairs & 2 & - \\
\hline
\end{tabular}

Table 2: Parameter values of YHM180-36 M PV panel.

\begin{tabular}{cc}
\hline Optimum operation voltage & $35.20 \mathrm{~V}$ \\
Optimum operation current & $5.11 \mathrm{~A}$ \\
Open-circuit voltage & $43 \mathrm{~V}$ \\
Short-circuit current & $5.5 \mathrm{~A}$ \\
Maximum power at STC & $180 \mathrm{~W}$ \\
Peak efficiency & $16 \%$ \\
Temp. Coefficient of $I_{s c}$ & $-(0.06 \pm 0.01) \% / k$ \\
Temp. Coefficient of $V_{o c}$ & $-(78 \pm 10) \mathrm{mV} / \mathrm{k}$ \\
Number of cells & 72 \\
\hline
\end{tabular}

\subsection{Performances Tests}

A step reference speed was applied at $\mathrm{t}=1 \mathrm{~s}$ and is equal to $157 \mathrm{rad} / \mathrm{s}$. The load torque is applied at $\mathrm{t}=5 \mathrm{~s}$. At $\mathrm{t}=7 \mathrm{~s}$, undergone a disturbance on the rotor resistance which has been increased by $50 \%$ from its rated value. The implemented control scheme based on ANFIS is compared to the classical PI control and adaptive control based on MRAS rotor resistance observer using the same speed profile and the same operating conditions.

Figures 15-17 show the simulations results for the classical PI without gains adaptation, classical PI control with MRAS rotor resistance observer and the proposed ANFIS control based PI gains adaptation. Figure 15 shows that the rotor speed decrease by almost $15 \mathrm{rad} / \mathrm{s}$ from its rated value, and the rotor speed error illustrated by figure 16 show that this error exceeds $9 \%$ when the rotor resistance undergone a variation in case of classical PI without gains adaptation.

Figure 17 shows the effect of sudden change on the shape of direct and quadratic flux, when a $50 \%$ increase of the rotor resistance is introduced, in case of classical PI control. Just at the moment of variation, the orientation of the fluxes is lost, which deteriorate the controllers performances.

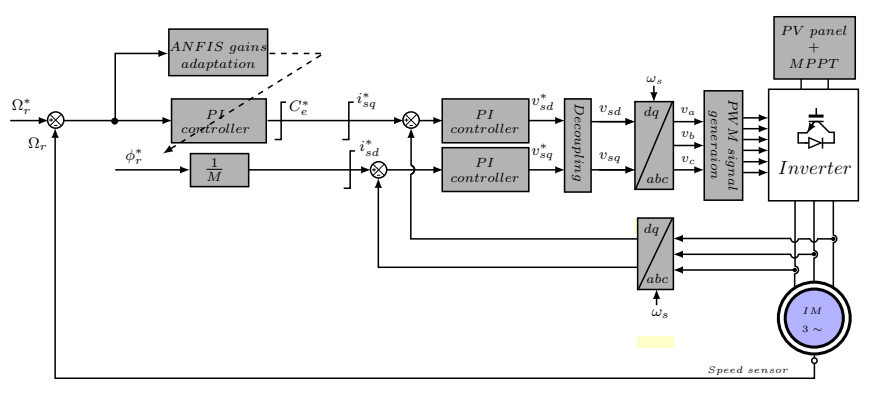

Figure 14: Block diagram of vector control with an adaptive fuzzy logic gains adaptation of the PI speed controller.

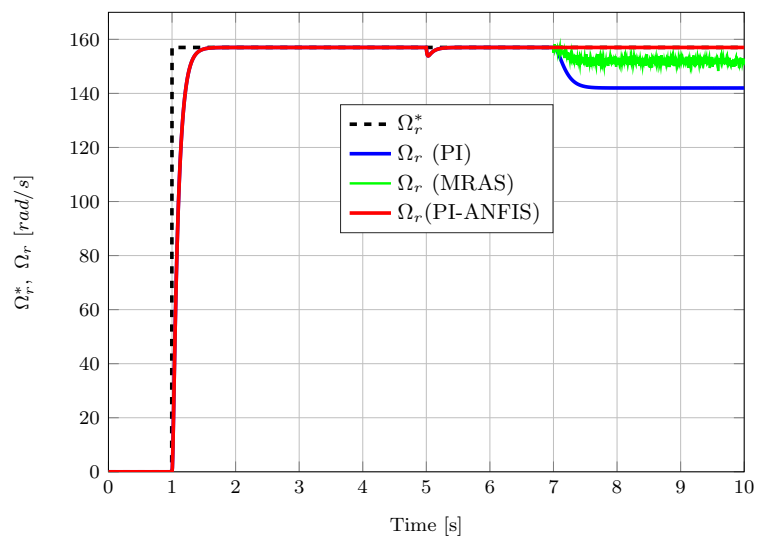

Figure 15: Rotor speed.

Figures 15-17 show also the performance of the adaptive control based ANFIS gains adaptation of the PI speed controller. The obtained result demonstrates that even if an increase the rotor resistance is introduced at $\mathrm{t}=7 \mathrm{~s}$, the proposed adaptive control still gives a good orientation of the rotor flux and a good speed tracking, with a speed error which doesn't exceed $0.5 \%$ of the rated value. However, the adaptive vector control based on MRAS rotor resistance observer does not guarantee a good tracking of the rotor speed as shown in Figure 15. In this case, when the rotor resistance undergoes a variation, the rotor speed decrease by almost $5 \mathrm{rad} / \mathrm{s}$ from its rated value with the appearance of ripples as shown in Figures 15-16. Figure 17 shows that using an MRAS rotor resistance observer does not guarantee a good fluxes orientation. 


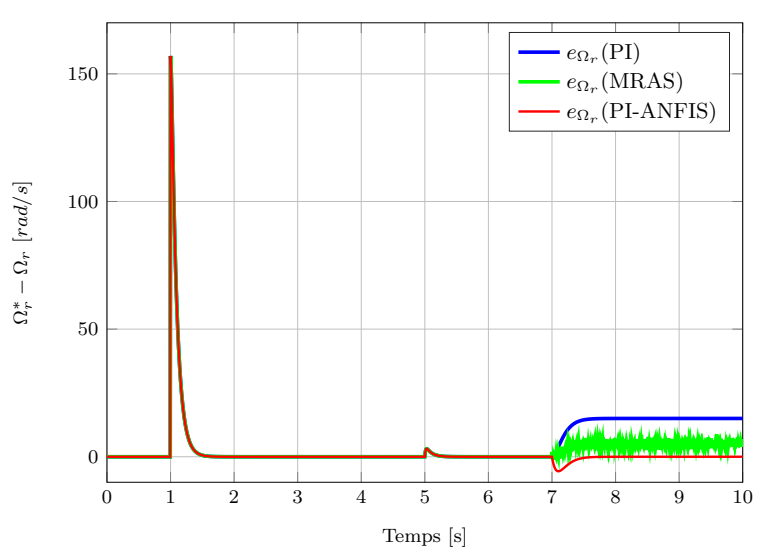

Figure 16: Rotor speed error.

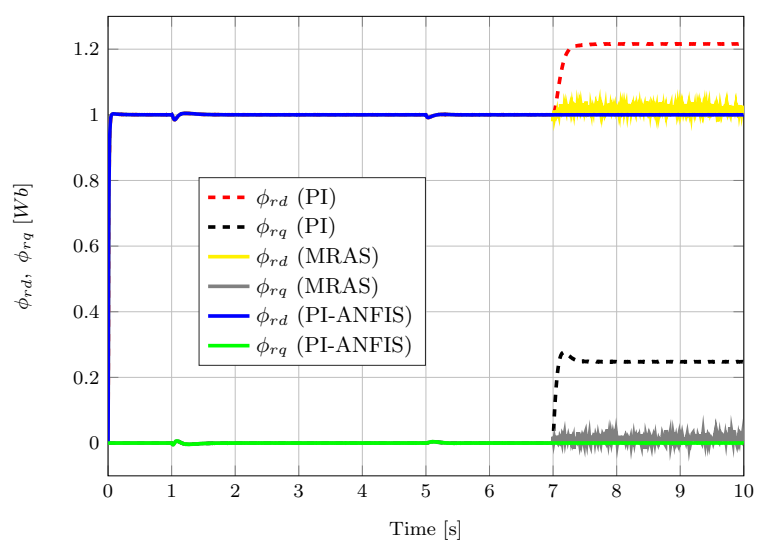

Figure 17: Rotor flux.

\subsection{Robustness Tests}

In order to test the performance of the proposed control scheme which is based on an adaptive proportional-integral ANFIS controller are again assessed by another three tests using the same condition mentioned in the previous subsection 4.1, which are performed to study the influence of the parametric variations for the inertia coefficient, the stator and rotor inductances of the induction motor. Simulations results of robustness tests illustrated by Figures 18-20 show clearly that the variation of $J, L_{s}$ and $L_{r}$ has practically no effect on the dynamics of speed response, even in the presence of a rotor resistance variation.

The obtained results show clearly that the proposed adaptive control based on ANFIS-PI gains adaptation has a powerful approach to allow high performance control. The obtained simulation results show also that the PI control with gains adaptation based on ANFIS can guarantee a high performance control of induction motor, and prove the efficiency of the proposed control scheme in terms of speed reference tracking in transients and stand-still operation, rotor flux orientation and load disturbances rejection, even in the presence of parametric variations.

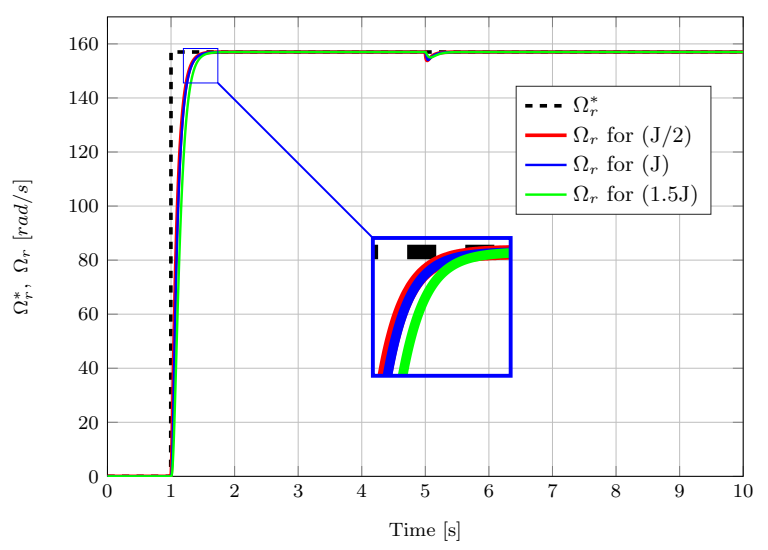

Figure 18: Rotor speed (case of $J$ variation).

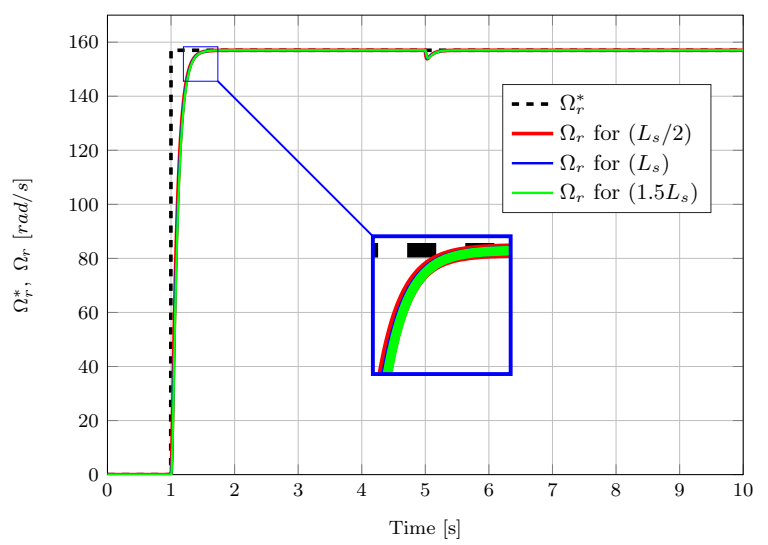

Figure 19: Rotor speed (case of $L_{s}$ variation).

Table 3 shows the quantitative performances in case of some parametric variations of the proposed adaptive proportional-integral ANFIS controller. The results illustrate globally that the variation of $J, L_{s}$ and $L_{r}$ does not deteriorate the performance of the proposed control. 


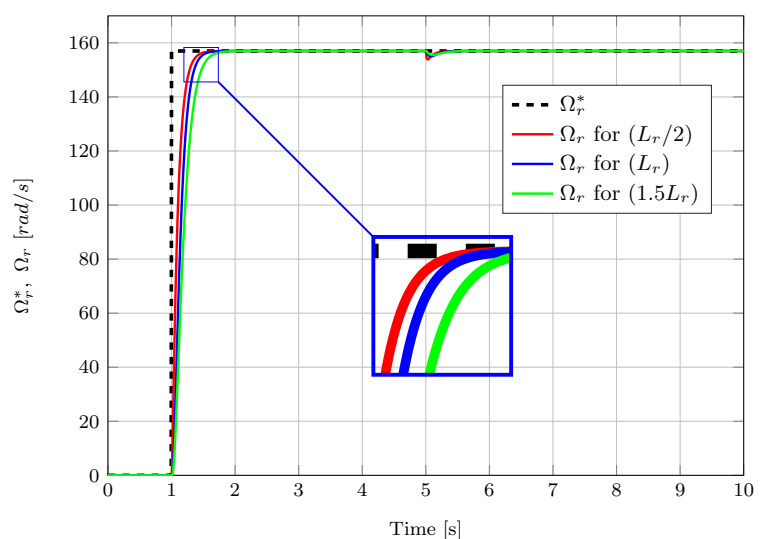

Figure 20: Rotor speed (case of $L_{r}$ variation).

Table 3: Quantitative performances of the proposed controller.

\begin{tabular}{|c|c|c|}
\hline & \multirow{2}{*}{$\begin{array}{c}\text { Adaptive proportional } \\
\text { integral ANFIS controller }\end{array}$} \\
\hline \multirow{2}{*}{ Parameter } & \multirow{2}{*}{ variations } & \\
\hline & & Settling time $\left(T_{r} \pm 5 \%\right)$ \\
\hline \multirow{3}{*}{$\begin{array}{c}\text { Inertia } \\
\text { coefficient }\end{array}$} & $\frac{J}{2}$ & $0.34 s$ \\
\hline & $J$ & $0.345 \mathrm{~s}$ \\
\hline & $1.5 \mathrm{~J}$ & $0.35 s$ \\
\hline \multirow{3}{*}{$\begin{array}{c}\text { Stator } \\
\text { inductance }\end{array}$} & $\frac{L_{s}}{2}$ & $0.344 s$ \\
\hline & $L_{s}$ & $0.345 s$ \\
\hline & $1.5 L_{s}$ & $0.346 s$ \\
\hline \multirow{3}{*}{$\begin{array}{c}\text { Rotor } \\
\text { inductance }\end{array}$} & $\frac{L_{r}}{2}$ & $0.275 s$ \\
\hline & $L_{r}$ & $0.34 s$ \\
\hline & $1.5 L_{r}$ & $0.46 s$ \\
\hline
\end{tabular}

\section{Conclusions}

The PI control with gains adaptation based on adaptive neuro-fuzzy inference system technique is developed in this paper. The proposed method is an alternative to handle the induction motor rotor resistance variation problem. This technique uses an adaptive mechanism of the PI gains which is ensured using an Adaptive Neuro-Fuzzy Inference System (ANFIS) for each gain $\left(k_{p}\right.$ and $\left.k_{i}\right)$. The proposed control scheme can guarantee a high performance compared to the classical PI control and the adaptive control using an MRAS rotor resistance observer. Simulation tests confirm the theoretical concepts and show that this type of adaptive control can overcomes the rotor resistance variation. The simulation results showed that the proposed control scheme can guarantee a good performance of the fact that the speed error exceeds $1 \%$ of the rated value.

\section{References:}

[1] H. Hamdi, C. Ben Regaya, A. Zaafouri, Realtime study of a photovoltaic system with boost converter using the PSO-RBF neural network algorithms in a MyRio controller, Solar Energy 183, 2019, pp. 1-16.

[2] H. Hamdi, C. Ben Regaya, A. Zaafouri, A sliding-neural network control of inductionmotor-pump supplied by photovoltaic generator, Prot Control Mod Power Syst 5, 1, 2020, pp. 117.

[3] H. Hamdi, C. Ben Regaya, A. Zaafouri, Performance improvement of a photovoltaic system with a radial basis function network based on particle swarms optimization, IEEE International Conference on Signal, Control and Communication (SCC), 2019.

[4] R. Saidur, A review on electrical motors energy use and energy savings, Renewable and Sustainable Energy Reviews, 14, 2010, pp. 877-98.

[5] J.T.E Fernando and T. Anbal, Induction motor downsizing as a low-cost strategy to save energy, Journal of Cleaner Production, 24, 2012, pp. 117-31.

[6] W. Chakchouk, C. Ben Regaya, A. Zaafouri, A. Sellami, An improved fuzzy logic control of irrigation station, 4th International Conference on Control, Decision and Information Technologies (CoDIT), 2017, pp. 259-264.

[7] C. Ben Regaya, W. Chakchouk, A. Zaafouri, A. Sellami, A. Chaari, Adaptive Discrete-time Backstepping Control of irrigation station, International Conference on Advanced Systems and Electric Technologies (IC-ASET), 2017, pp. 158-163.

[8] W. Chakchouk, C. Ben Regaya, A. Zaafouri, A. Sellami, Fuzzy supervisor approach design based-switching controller for Pumping station: Experimental validation, Mathematical Problems in Engineering, 2017, pp. 1-12.

[9] F. Mehazzem Fateh and A. Reama, Comparative study of integral and classical backstepping controllers in IFOC of induction motor fed by voltage source inverter, International Journal of Hydrogen Energy, 42(28), 2017, pp. 17953-64.

[10] C. Ben Regaya, F. Farhani, Z. Abderrahmen, C. Abdelkader, A novel adaptive control method for induction motor based on Backstepping approach using dSpace DS 1104 control board, Mechanical Systems and Signal Processing, 100, 2018, pp. 466-81. 
[11] A. Karim, A. Lakrim, D. Tahri, Reduced Time Domain Behavioral Model of Three-Wire Shielded Power Cables, International Journal of Circuits, Systems and signal processing, 13, 2019, pp. 617-624.

[12] F. Blaschke, The principle of field oriented as applied to the new Tran vector closed-loop control system for rotating machine, Siemens Review, 39(4), 1972, pp. 217-20.

[13] I. Takahashi, N. Toshihiko, A New QuickResponse and High-Efficiency Control Strategy of an Induction Motor, IEEE Transactions on Industry Applications, 1A-22(5), 1986, pp. 820 27.

[14] L. Amezquita-Brooks, E. Liceaga-Castro, J. Liceaga-Castro, C. Ugalde-Loo, Flux-torque cross-coupling analysis of FOC schemes: Novel perturbation rejection characteristics, ISA Transactions 58, 2015, pp. 446-61.

[15] I. Nouira El Badsi, B. El Badsi, A. Masmoudi, Experimental Evaluation of RFOC and DTC Strategies for B6-VSI Fed Induction Motor Drives, 17th international conference on Sciences and Techniques of Automatic control \& computer engineering, STA', 2016, pp. 488-95.

[16] M. Nait Said, M. Benbouzid, Induction motors direct field oriented control with robust on-line tuning of rotor resistance, IEEE Transactions on Energy Conversion, 14(4), 1999, pp. 10381042.

[17] A. Bohari, W. Utomo, Z. Haron, N. Zin, S. Sim, R. Ariff, Speed Tracking of Indirect Field Oriented Control Induction Motor Using Neural Network, Procedia Technology, 11, 2013, pp. 14146.

[18] L. Taneja, S. Kumar, R Kumar, Current regulated induction motor drive with IFOC, In 2014 IEEE 6th India International Conference on Power Electronics (IICPE), 2014, pp. 1-5.

[19] C. Ben Regaya, F. Farhani, A. Zaafouri, A. Chaari, Comparison between two methods for adjusting the rotor resistance, International Review on Modelling and Simulations (I.RE.MO.S), 5(2), 2012, pp. 938-44.

[20] C. Ben Regaya, A. Zaafouri, A. Chaari, Electric drive control with rotor resistance and rotor speed observers based on fuzzy logic, Mathematical Problems in Engineering, 2014, pp. 1-9.

[21] C. Ben Regaya, A. Zaafouri and A. Chaari, A new sliding mode speed observer of electric motor drive based on fuzzy-logic, Acta Polytechnica Hungarica, 11(3), 2014, pp. 219-232.
[22] C. Ben Regaya, F. Farhani, A. Zaafouri and A. Chaari, High-performance control of im using mras-fuzzy logic observer, International Journal of Tomography and Simulation, 30(2), 2017, pp. 40-51.

[23] M. Gayathri, S. Himavathi and R. Sankaran, Comparison of rotor flux and reactive power based mras rotor resistance estimators for vector controlled induction motor drive, International Conference on Advances in Engineering, Science and Management (ICAESM), India, 2012, pp. 183-189.

[24] A. Zaafouri, C. Ben Regaya, H. Ben Azza and A. Chaari, Dsp-based adaptive backstepping using the tracking errors for high-performance sensorless speed control of induction motor drive, ISA Transactions, 60, 2016, pp. 333-347.

[25] Y. Zahraoui, M. Akherraz, and S. Elbadoui, Improvement of Induction Motor State Observation: Extended Kalman Filter Versus Adaptive Luenberger Observer, 15, WSEAS TRANSACTIONS on SYSTEMS and CONTROL, 2020, pp. 120-130.

[26] C. Ben Regaya, Contribution la synthese de lois de commande robuste de la machine induction triphase : Validation exprimentale, Ph.D. Thesis, Ecole Suprieure des Sciences et Techniques de Tunis, 2016.

[27] S. Motahhir, A. E. Ghzizal, and A. Derouich, Modelisation et commande dun panneau photovoltaque, $2 \mathrm{me}$ dition du Congrs Internatinal de Gnie Industriel et Management des Systmes, 2015, pp. 118.

[28] H. Souilem, and N. Derbel, Neuro-Fuzzy Control of Vehicle Active Suspension System, International Journal of Circuits, Systems and Signal processing, 12, 2018, pp. 423431.

\section{Creative Commons Attribution License 4.0 (Attribution 4.0 International, CC BY 4.0)}

This article is published under the terms of the Creative Commons Attribution License 4.0 https://creativecommons.org/licenses/by/4.0/deed.en_US 